\title{
VIBRATION MEASUREMENTS AT A NEW MONUMENT IN NUR- SULTAN CITY
}

\author{
*Abdulla R. Omarov ${ }^{1}$, Marat Kuderin², Askar Zhussupbekov${ }^{1}$, Victor N.Kaliakin ${ }^{3}$ and Sultan Iskakov ${ }^{1}$ \\ ${ }^{1}$ Department of Civil Engineering, L.N. Gumilyov Eurasian National University, Kazakhstan; ${ }^{2}$ Faculty of \\ Architecture and Construction, S. Toraighyrov Pavlodar State University, Kazakhstan; ${ }^{3}$ Department of Civil \\ and Environmental Engineering, University of Delaware, US
}

*Corresponding Author, Received: 29 March 2021, Revised: 13 July 2021, Accepted: 26 July 2021

\begin{abstract}
The construction of unique structures is complicated by the fact that codes and standards do not exactly apply to such structures. This paper presents an overview of the analysis, design, wind tunnel testing and field monitoring of a $70 \mathrm{~m}$ high monument that was constructed in the capital city of Nur-Sultan in the Republic of Kazakhstan. This overview constitutes a useful example of the constraints imposed by such unique, one-of-a-kind structures. The natural frequencies of the monument, determined from measured accelerations, differed slightly from analytically computed values. Scale models were constructed to study the response of the monument. Pressure distribution on the surfaces of a scaled model of the building was recorded at different wind speeds and wind angles. These models were equipped with sensors that measured the average component of pressure and the pulsating component of pressure. The effect of the different wind angles in determining the drag coefficient on the building was also performed. Based on the aforementioned analyses and in light of the results of the wind tunnel tests on a scale model of the monument, a 4-chord truss was selected as the structural backbone of the monument. The chords consist of pipes that are connected by a system of webs. Cladding is then attached to the truss to give the monument its desired esthetics and to facilitate its aerodynamics. The tuning of two mass damper systems installed in the monument is also described.
\end{abstract}

Keywords: Monument, Vibration Monitoring, Damper Tuning, Wind Speed, TMD

\section{INTRODUCTION}

In recent years, many high-rise buildings, towers and monuments have been built all over the world [1-6]. Such structures often have large aspect ratios, low fundamental natural frequencies and small structural damping. Consequently, they are extremely prone to wind-induced vibrations, especially Vortex-Induced Vibration (VIV) in the across-wind direction. This indicates that some countermeasures should be adopted to reduce the across wind VIV response of high-rise buildings, towers and monuments.

Many types of aerodynamic countermeasures, such as tapering, corner modifications and surface texturing have been adopted to reduce the windinduced VIV response of high-rise buildings by changing their configuration [1-6].

Wind loads are one of the main types of loads that high-rise buildings, towers and monuments are subjected to. Consequently, such loads are very important in the design of such structures. The intensity of this loading and its distribution over the surface of a structure is determined by the wind speed and direction at the construction site, the geometric shape and dimensions of the structure, as well as the dynamic properties of the associated structural elements. In urban conditions, wind flows are formed due to the flow of air around artificial objects such as buildings, park areas, etc. The result is a very turbulent air flow with large vertical components of wind speed.

The main calculated provisions of the subsection "Design wind load" of the standards used for the project [7] are based on experimental results obtained in the mid-70s. Basically, this part of the normative document is intended for the calculation of loads for the simplest types of structures. Experimental data obtained over the past 40 years [8-11] show that the values of aerodynamic coefficients adopted in this section of the standards used for the project, as well as the existing method of normalizing the pulsation component of the wind load, cannot be directly used in the design of enclosing structures. Instead, they need to be suitably adjusted in order to produce more rational designs.

The analysis and design of unique, one-of-akind structures is also complicated by the fact that codes and standards typically do not exactly apply to such structures. Consequently, analytical design calculations for such structures must sometimes be supplemented by laboratory tests on scale models of the prototype. Once constructed, it is desirable to monitor the performance of the structure in order to better ascertain whether it behaves as 
assumed during its analysis, testing and design.

This paper discusses a $70 \mathrm{~m}$ high monument that was constructed in the capital city of NurSultan in the Republic of Kazakhstan on the occasion of the 2017 World Expo (see Fig.1). An overview of the analysis, design, and wind tunnel testing is first presented. This is followed by a discussion of the instrumentation and field monitoring of the monument [12-16].

\section{RESEARCH SIGNIFICANCE}

The instrumentation and health monitoring of structures is a generally well-established field. Ideally, the performance of a structure will be continuously monitored during its life. Practically, however, it is not always possible to install instruments and continuously monitor the response of all structures. This is especially true of unique structures such as monuments. Such structures are, however, typically not designed to house inhabitants. Consequently, they may not have sufficient space to house extensive instrumentation. Even if such instrumentation is installed, it may not be readily accessible for adjustment, data collection and modification.

The monument discussed in this paper is a prime example of a unique structure that does not lend itself to easy health monitoring. Consequently, the account of the analysis, design, testing, and field monitoring serves as a useful example of the constraints imposed by such structures.
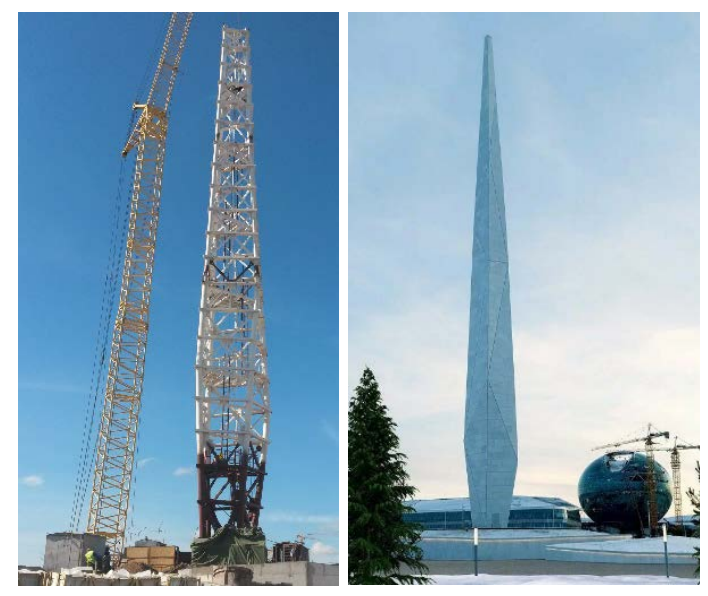

Fig. $170 \mathrm{~m}$ high monument in Nur-Sultan, Kazakhstan. a) Structural backbone, b) Finished structure with cladding

\section{OVERVIEW OF THE MONUMENT}

The structural backbone of the monument is a 4-chord truss (Fig.1a). The chords consist of pipes that are connected by a system of webs. Cladding is then attached to the truss [1]. The resulting structure (Fig.1b) casts a "broken line" projection in the horizontal plane.

Such a structure is rather unique, with rather complex geometry and structural details that have little or no precedent. It is thus timely to give an overview of the analysis and design of the monument.

\section{ANALYSIS AND DESIGN OF THE MONUMENT}

An architectural rendering of the $70 \mathrm{~m}$ high monument is shown schematically in Fig.1. Such a structure is rather unique, with rather complex geometry and structural details that have little or no precedent.

The nature of the monument places it under the "Building Responsibility Level I" (Advanced) design category. The monument was designed for a snow load of $100 \mathrm{~kg} / \mathrm{m}^{2}$, which is consistent with the requirements for Snow Region III, according to SNIP 2.01.07.-85*[17]. The extreme design temperature is $-35^{\circ} \mathrm{C}$. The design wind pressure was $38 \mathrm{~kg} / \mathrm{m}^{2}$, which is consistent with the requirements for Wind Region III according to SNIP 2.01.07-85*[17].

To determine suitable design wind velocities at the monument site, data recorded since 1955 was used (see Fig.2).

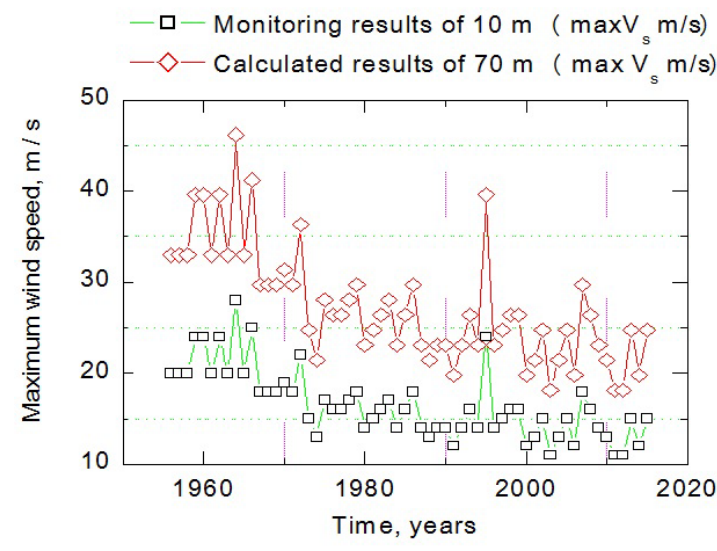

Fig. 2 Maximum wind speed values in measured in Nur-Sultan for the last 60 years

The five-year maximum wind speed was 31 $\mathrm{m} / \mathrm{s}$; the ten-year maximum speed was $33 \mathrm{~m} / \mathrm{s}$; finally, the 100-year maximum speed was approximately $40 \mathrm{~m} / \mathrm{s}$. The average annual wind speed is $5.2 \mathrm{~m} / \mathrm{s}$. Finally, the site experiences wind 280 to 300 days per year.

The results of model tests of the monument in a wind tunnel revealed that the most pronounced regular vortex separation from the surface of the structure, which causes its resonant excitation, occurs when the flow directions are perpendicular to its edges at a height of $56 \mathrm{~m}$. At the same time, 
with resonant vortex shedding of the structure, it is possible to accumulate fatigue damage in the structure [8-10].

The intensity of the vortex shedding pressure $\mathrm{F}(\mathrm{z})$, acting in a direction perpendicular to an indicated wind direction, is determined from the following formula Eq. (1) [18]:

$$
F_{(Z)}=0.75 \pi V_{c r}^{2} c_{y} \phi(z) d / \delta,
$$

where,

$\mathrm{z}$ is the coordinate along the axis of the structure;

$\mathrm{V}_{\mathrm{cr}}=8 \mathrm{~m} / \mathrm{s}$ is the wind speed used in the calculation;

$\mathrm{c}_{\mathrm{y}}=0.35$ is the aerodynamic shear force coefficient;

$\delta=0.05$ is the logarithmic decrement for oscillations; and,

$\mathrm{d}=$ the transverse dimension of the monument;

$\phi(\mathrm{z})$ is the form of natural flexural vibrations in directions perpendicular to the wind flow.

When calculating a structure for resonant vortex excitation, the effects of wind load and vortex shedding pressure are taken into account simultaneously.

Test results of structures of this type show that, in addition to their geometric shape, the magnitude and distribution of aerodynamic coefficients can be influenced by several factors that are usually not taken into account in design practice. It is thus important to note that other buildings and structures are located on the site under consideration; these, in turn, contribute to a change in the direction of wind flow and, as a result, to a change in the existing wind loads.

The code SP 20.13330.2011 "Loads and Impacts” [7], as well as other domestic and foreign regulatory documents, do not provide data on the distribution of aerodynamic coefficients for structures of this type. In such cases, aerodynamic coefficients are usually best determined based on the results of aerodynamic tests performed on scale models of a structure. Consequently, an experimental study of the distribution of aerodynamic coefficients over the surfaces of scale models of the monument was carried out in a specialized wind tunnel [19-20]. The purpose of these experiments was to determine the calculated wind loads and peak values of wind loads acting on the structure.

\section{OVERVIEW OF WIND TUNNEL TESTS}

The magnitude and distribution of aerodynamic characteristics over the surface of a structure are known to substantially depend on the nature and structure of the incoming flow and on the degree of its correspondence to real wind flows [19-20]. Thus, before performing tests on scale models of the monument, the roughness elements were removed from the floor of the aerodynamic installation so that the wind flow corresponded to "type A" [18] terrain, which was determined to be typical for the conditions of the construction site when subjected to different wind directions.

Three scale models were constructed to study the response of the monument. Each of these models was in accordance with the preliminary design drawings. Each was made of wood, sheet polystyrene and polyvinyl chloride. These models were equipped with sensors that measured the average component of pressure and the pulsating component of pressure. In the course of experimental studies, the flow incidence angle varied with a step $\Delta \alpha=10^{\circ}$.

The first model was a 1:100 scale representation of the entire monument. The other two models were 1:40 scale representations of portions of the monument. The first of these represented the lower $33.6 \mathrm{~m}$ of the monument. The final model represented the portion of the monument above 33.6 m (see Fig.3).

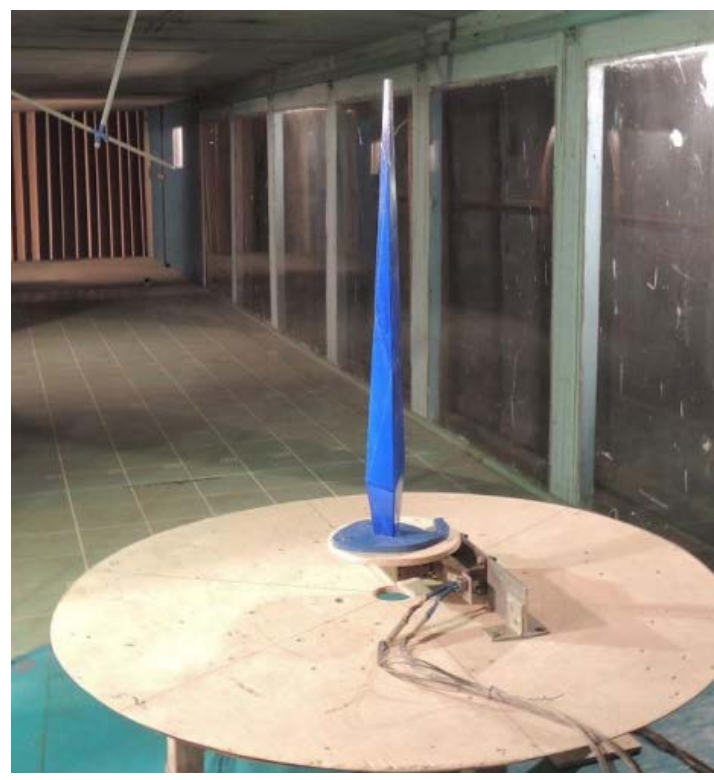

Fig. 3 General view of the building model in a wind tunnel

In a given wind tunnel test, pressure pulsations $\mathrm{p}(t)$ were recorded during the duration $T=15 \mathrm{sec}$. with a time step $\Delta t=0.002 \mathrm{sec}$. Using equation (2), the recorded values $\mathrm{p}_{i}(i=1, \ldots 1000)$ were then smoothed over the interval $\Delta \mathrm{t}=0.01 \mathrm{sec}$. The pressures obtained in this, taking into account scale factors, correspond to 1-3 seconds of wind pressure for a real structure. It is timely to note that a similar interval of averaging wind speeds and 
wind loads is adopted in the regulatory documents of many countries [7-11].

$$
\widetilde{p}_{i}=\frac{1}{10} \sum_{j=1}^{10} p_{10(i-1)+j}, i=1, \ldots 1000
$$

For the 1:100 scale model, tests were carried out in which the total loads were determined with a step $\Delta \alpha=5^{\circ}$. The results of these tests were used to assess the possibility of the appearance of aerodynamically unstable oscillations of the galloping type.

The aerodynamic coefficients of the total pressure $c_{p}$ are defined as the algebraic difference between the aerodynamic coefficients of the external $c_{e}$ and internal pressures $c_{i}$; i.e.,

$$
c_{p}=C_{e}-C_{i}
$$

The values of $c_{e}$ for vertical surfaces of the structure at various angles of attack $\beta^{\circ}$ (Fig. 4) are given in Figs.5 and Fig.6.

The locations of the points at which these coefficients are determined are shown in Figs. 8 and Fig.9.

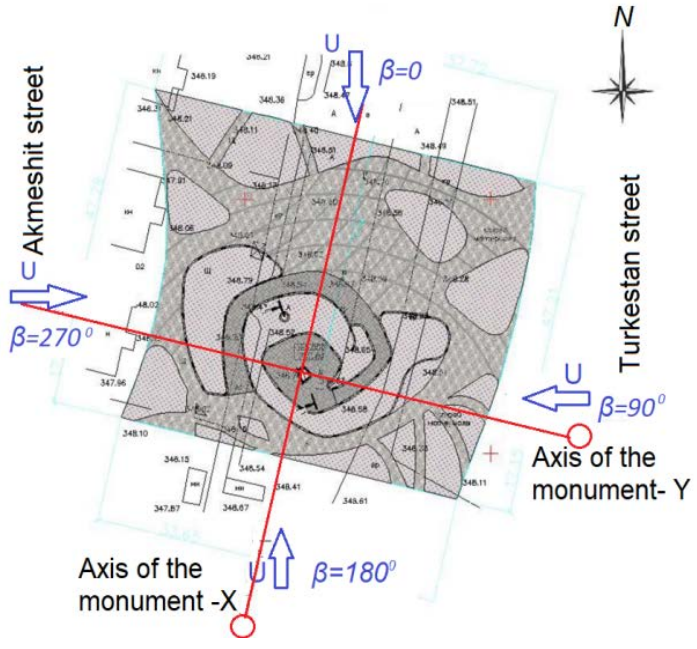

Fig. 4 Construction scheme

During the tests, the relative blockage $\phi$ of the cross-section of the working tube did not exceed $8 \%$, which meets the requirements for this kind of experimental research [20-21].

The average and pulsation pressure components were measured at 20 points in horizontal sections located at levels $\mathrm{z}=6 \mathrm{~m}$ and $66 \mathrm{~m}$ (see Figs.7 and Fig.8, respectively). Figs.9 and Fig.10 graphically summarize the extreme values of the experimentally determined aerodynamic coefficients.

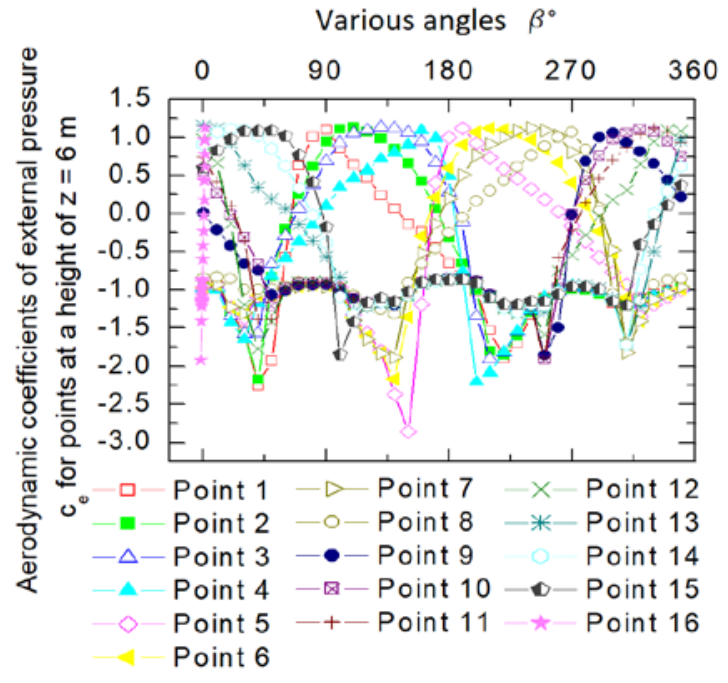

Fig. 5 Aerodynamic coefficients of external pressure $c_{e}$ for points at a height of $\mathrm{z}=6 \mathrm{~m}$

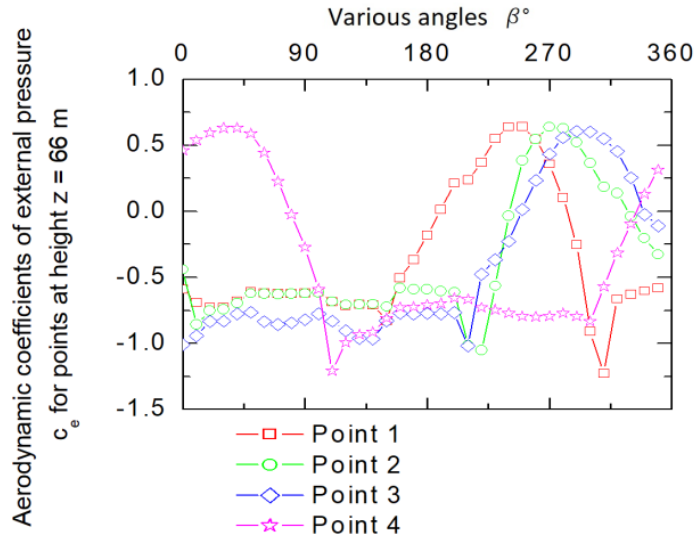

Fig. 6 Aerodynamic coefficients of external pressure $c_{e}$ for points at a height of $\mathrm{z}=66 \mathrm{~m}$

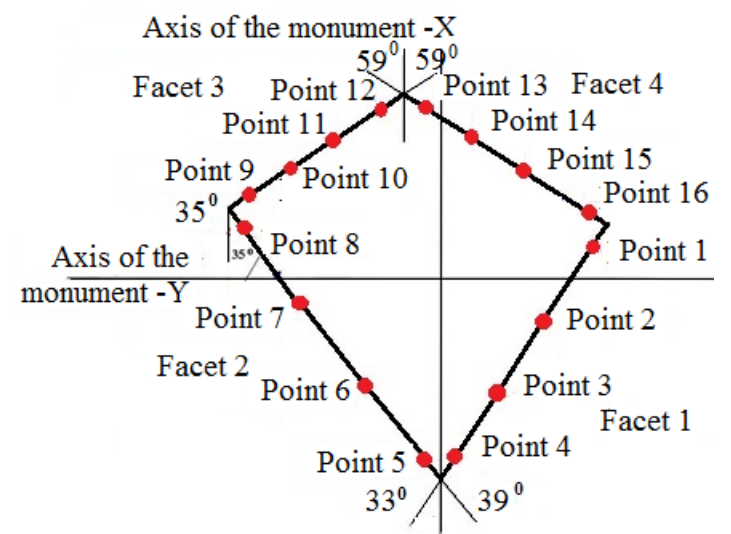

Fig. 7 Location of points at a height of $\mathrm{z}=6 \mathrm{~m}$, in which the aerodynamic coefficients are determined 


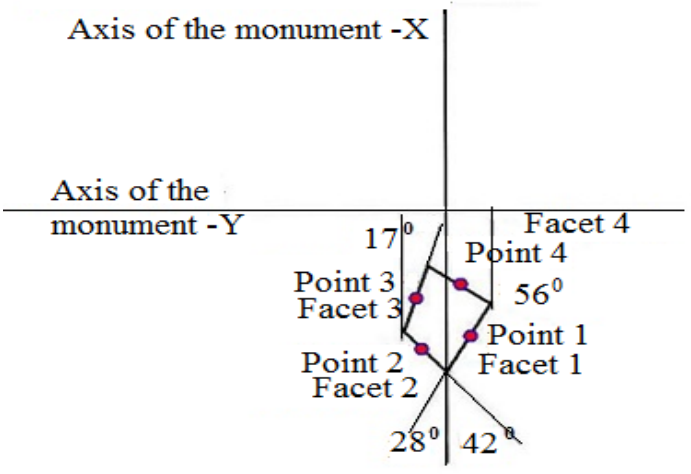

Fig. 8 Location of points at a height of $\mathrm{z}=66 \mathrm{~m}$, in which the aerodynamic coefficients are determined

Based on the aforementioned analyses, and in light of the results of the wind tunnel tests on a scale model of the monument, a 4-chord truss was selected as the structural backbone of the monument. The chords consist of pipes that are connected by a system of webs. Cladding is then attached to the truss to give the monument its desired esthetics and to facilitate its aerodynamics.

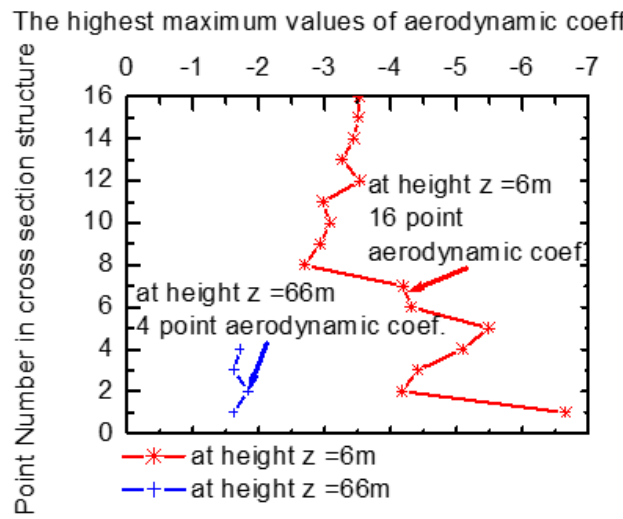

Fig. 9 Highest maximum values of aerodynamic coefficients

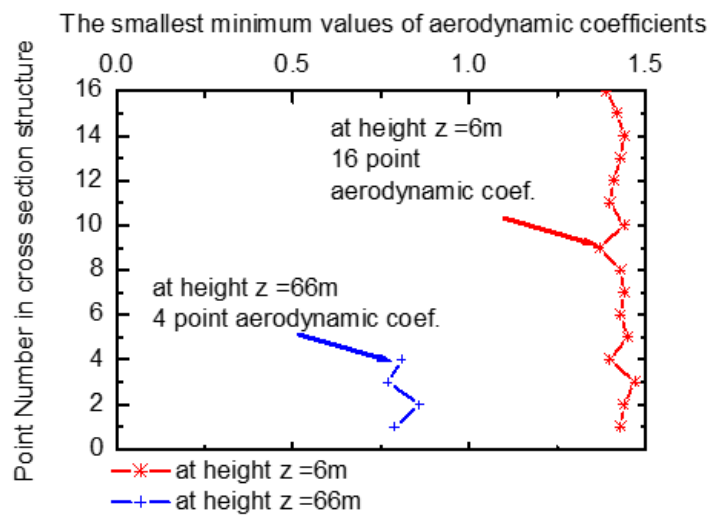

Fig. 10 Smallest minimum values of aerodynamic coefficients

\section{VIBRATION MEASUREMENTS FOR DETERMINATION OF DYNAMIC RESPONSE}

Due to its height $(70 \mathrm{~m})$ and to the fact that it is frequently subjected to wind loads, the monument will exhibit various levels of diurnal vibrations. To account for the effect of dynamic loading, structures such as the monument are designed assuming the presence of additional static forces that are included into the design in order to indirectly account for such effects. Although such design approaches tend to be conservative, they cannot properly account for the interaction of the foundation soil with the structure. Instead, such soil-structure interaction is often best characterized by monitoring the dynamic response of the structure as it is subjected to dynamic in-service loads [22].

\subsection{Ambient Vibration Measurements}

The measurement of structural vibrations can be used to determine stresses. In a given structure, stresses are directly related to the deformations. Such stresses can likewise be determined from vibration measurements. For example, peak stresses are associated with peak velocities. Based on the results of vibration measurements, it is possible to determine stresses and to compare them against acceptable design values for the structure. In general, the state of a structure depends not only on the peak stresses but also on the accumulated fatigue. Fatigue effects are, however, usually ignored if the dynamic stress is less than $10 \%$ of the design static stress [22].

\subsection{Description of the Ambient Vibration Measurements}

Natural frequencies are often determined from measured accelerations. The basic assumption for the determination of modal parameters on the basis of ambient vibrations is that the ambient energy input can be idealized as white noise in the relevant frequency range. This means that all mode shapes within this frequency range are excited with a constant amplitude and phase. However, when ambient vibration measurements are carried out at a construction site, harmonic excitations by noninterrupted construction activities can contribute to the signal. In this case, the excitation is not perfect white noise [22].

The purpose of the ambient vibration measurements at the monument was to determine the natural frequencies of the structure. Based on the evaluated natural frequencies, the pendulum damping system used in the monument could, if necessary, then be adjusted. 
An ambient vibration measurement is very useful for the determination of natural frequencies, mode shapes and damping, because (a) the procedure is simple and not time-consuming, and (b) an artificial excitation does not need to be applied.

The following equipment was used to measure structural vibrations at the monument [22-23]:

- Two axial Force Balance Accelerometers BMC, type ACS1002-USB with precision of $\pm 1 \mathrm{~m} / \mathrm{s}^{2}$. Fig.11 shows the location of the accelerometers, as they were attached to the monument.

- Dasylab 2013 data logger software, run on a notebook computer.

During the time period spanning from 7 to 11 November 2016, the ambient vibrations of the monument were measured several times for 15 minute intervals with a sampling rate of $200 \mathrm{~Hz}$. It is during this time that access was available to the two TMDs installed in the monument.

The vibration data were next post-processed using the DIAdem software. Fig.12 shows the averaged results of the ambient vibration measurement after FFT analysis of the $\mathrm{x}$ - and $\mathrm{y}$ sensor signals. The first four natural frequencies of the monument were estimated to be $0.70,0.82$, 2.39 and $2.63 \mathrm{~Hz}$.

\subsection{Results of the Ambient Vibration Measurements}

It is timely to note that, using analytical calculations, the first four natural frequencies were estimated to be $0.56,0.64,2.01$ and $2.24 \mathrm{~Hz}$ [12$13]$.

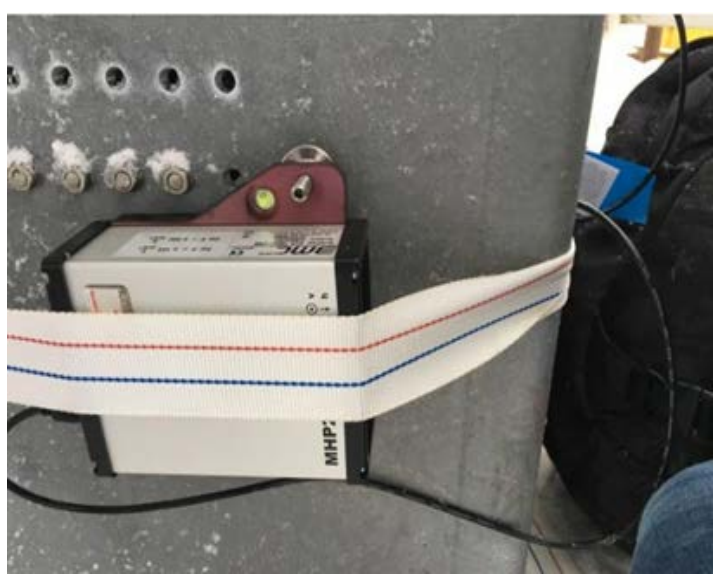

Fig. 11 Location of the accelerometers (position of sensor at level $36 \mathrm{~m}$ )

\subsection{Damper Adjustment}

Two sets of TMDs were installed in the monument. One of the benefits of measuring the natural frequencies of the monument before the completion of construction is that the dampers can be adjusted. Once construction is completed, it will be extremely difficult to access these dampers [2223].

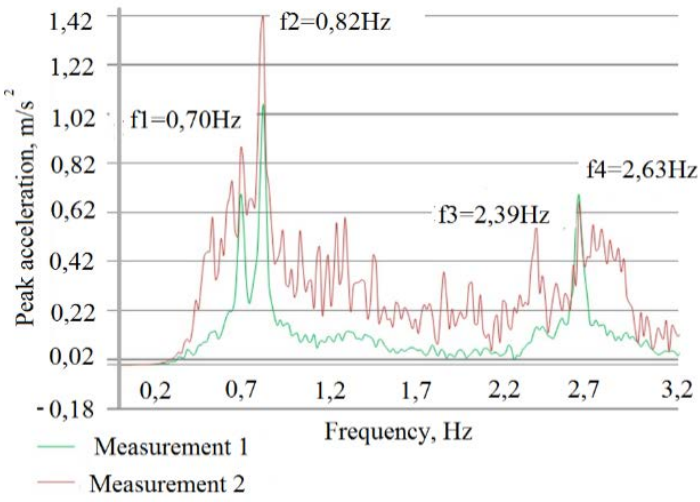

Fig. 12 Results of frequency spectrum analysis

Using adjustment shims (one shim per friction plate), the dampers were thus adjusted based on the natural frequencies measured for the monument. Table 1 summarize the associated information (Fig.13a shows TMD 1, while Fig.13b shows TMD 2).

a)

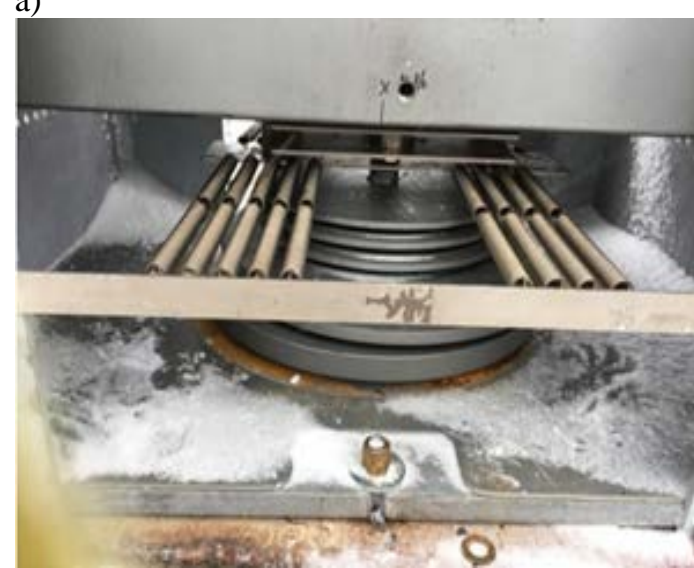

b)

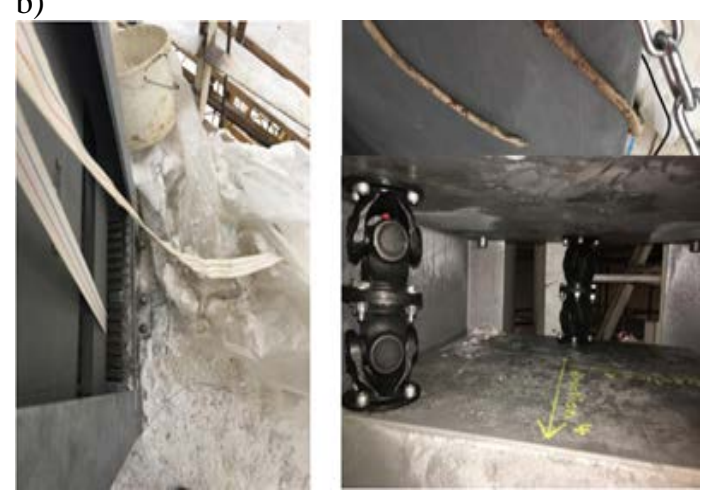

Fig. 13 Final settings: a) for TMD 1; b) for TMD 2 
Table 1 Final settings for TMD 1 and TMD 2 (see Figs.13a and Fig.13b)

\begin{tabular}{ccc}
\hline $\begin{array}{c}\text { Final settings for } \\
\text { TMD 1 }\end{array}$ & Direction \#1 & Direction \#2 \\
\hline $\begin{array}{c}\text { No of tuning springs } \\
\text { Frequency, Hz }\end{array}$ & 0.57 & 18 \\
\hline $\begin{array}{c}\text { Damping within SLS } \\
\text { range, kNs/m }\end{array}$ & 1.26 \\
\hline \multicolumn{2}{c}{ Final settings for TMD 2 } \\
\hline $\begin{array}{c}\text { No of tuning springs } \\
\text { Frequency, Hz }\end{array}$ & 11 & 28 \\
\hline $\begin{array}{c}\text { Damping within SLS } \\
\text { range, } \mathrm{kNs} / \mathrm{m}\end{array}$ & 2.92 \\
\hline
\end{tabular}

Now that the monument is completed, it is recommended that, if possible, the natural frequencies be again measured for verification.

\section{SUMMARY AND CONCLUSION}

This paper discussed a $70 \mathrm{~m}$ high monument that was constructed in the capital city of NurSultan in the Republic of Kazakhstan on the occasion of the 2017 World Expo. Since the monument is unique and rather complex, domestic and foreign regulatory documents, do not provide data on the distribution of aerodynamic coefficients for the enclosing structures of structures of this type.

An overview of the analysis, design, and wind tunnel testing on scale models of the monument has also been presented.

The maximum and minimum values of aerodynamic coefficients, determined at various angles of attack $\beta^{\circ}$ for the vertical surfaces of the structure, were also presented. The largest and smallest values of these coefficients, regardless of the angle of attack, are shown. The position of the sensors in which the pressure pulsations were recorded is shown in. Consequently, in the structure under consideration, unstable aerodynamic oscillations of a galloping type can possibly be excited. To prevent this, the following measures can be used:

- Perforation of the upper second surface of the structure;

- Installation of enclosing panels with a gap (slot-like perforation);

- Installation of vibration dampers.

In such cases, aerodynamic coefficients are usually determined based on model aerodynamic test data. Moreover, the test results of structures of this type show that, in addition to their geometric shape, the magnitude and distribution of aerodynamic coefficients can be influenced by several factors that are usually not taken into account in design practice. Therefore, it is very important to conduct field vibration monitoring.

This paper also presented the results of field monitoring of vibrations measured for the monument during the time period from 7 to 11 November 2016. It is during this time that access was available to the two tuned mass damper (TMD) systems installed in the monument.

The preliminary measured frequencies of modes 3 and 4 are a little bit higher than the expected ones.

The results of the vibration measurements allowed for the adjustment of the two TMDs installed in the monument.

\section{REFERENCES}

[1] González-Roubaud, E., Pérez-Osorio, D. and Prieto, C. "Review of commercial thermal energy storage in concentrated solar power plants: Steam vs. molten salts", Renew. Sustain. Energy Rev., Vol. 80, 2017, pp133148.

[2] Tahri, M., Hakdaoui, M. and Maanan, M. "The evaluation of solar farm locations applying geographic information system and multicriteria decision-making methods: Case study in southern Morocco", Vol. 51, 2015, pp13541362.

[3] Quan, Y. and Gu, M. "Experimental evaluation of aerodynamic damping of square super highrise buildings", Wind Struct., Int. J., Vol. 8, Issue 5, 2005, pp309-324.

[4] Tanaka, H., Tamura, T., Ohtake, K., Nakai, M. and Kim, Y.C. "Experimental investigation of aerodynamic forces and wind pressures acting on tall buildings with various unconventional configurations", J. Wind Eng. Ind. Aerodyn. 2012, pp179-191.

[5] Bandi, E.K., Tamura, Y., Yoshida, A., Kim, Y.C. and Yang, Q.S. "Experimental investigation on aerodynamic characteristics of various triangular-section high-rise buildings”, J. Wind Eng. Ind. Aerodyn., 2013, pp60-68.

[6] Kim, Y.C., Tamura, Y., Tanaka, H., Ohtake, K., Bandi, E.K. and Yoshida, A. "Windinduced responses of super-tall buildings with various atypical building shapes”, J. Wind Eng. Ind. Aerodyn., Vol. 133, 2014, pp191199.

[7] SP 20.13330.2011 "Loads and Impacts", Russian, 2011.

[8] Eurocode 1: Actions on structures - General actions - Part 1-4: Wind actions, CEN, 2005. p146

[9] American Society of Civil Engineers. Minimum design loads for buildings and other structures. ANSI/ASCE 7-95, ASCE, New 
York, 1998.

[10] Air Recommendations for Loads on Buildings. Chapter 6. Wind Loads. Architectural Institute of Japan.

[11] Standard Australia. Minimum design loads on structures. Part 2: Wind Loads. Standards Australia. North Sydney, 1989.

[12] Zhussupbekov A., Sultanov G., Omarov A. The Complexity of piling tests in problematical soil ground of Kazakhstan. Design and Analysis of Piled Raft Foundations -2017, Published in Taiwan by Tamkang University Press, 2017, pp169-176.

[13] Omarov, A.R., Zhussupbekov, A.Z., Tulegulov, A.D., Zhukenova, G.A., Tanyrbergenova, G.K. "The analysis of the piling tests on construction site "The future of the free country"' Proc. of the 8th Asian Young Geotechnical Engineers Conference, Astana, 2016, pp127-130.

[14]Zhussupbekov, A., Morev, I., Omarov, A., Borgekova, K., Zhukenova, G. Geotechnical considerations of piling testing in problematical soils of West Kazakhstan. International Journal of GEOMATE. Vol. 15, Issue 47, 2018, pp111-117.

[15] Zhussupbekov, A., Iwasaki, Y., Omarov, A., Tanyrbergenova, G., Akhazhanov, S. Complex of static loading tests of bored piles. International Journal of GEOMATE. Vol. 16, Issue 58, 2019, pp8-13.

[16]Zhussupbekov, A., Omarov, A., Tanyrbergenova, G. Design of anchored diaphragm wall for deep excavation.
International Journal of GEOMATE, Vol. 16, Issue 58, 2019, pp139-144.

[17] SNIP 2.01.07.-85, "Loads and Impacts", 1985.

[18]MDS 20-1.2006, Temporary recommendations for the assignment of loads and effects affecting multifunctional high-rise buildings, 2006.

[19] Khozyainov B.P., Berezin M.A. Methodology for windmill testing in the wind tunnel 3-AT$17.5 / 3$ of the UNIKON company, Vestn., KuzGTU, Vol. 4, 2000, pp38-42.

[20] Khozyainov, B.P., Kostin, I.G., Determination of aerodynamic characteristics of turbine vanes with vertical rotation axis. Thermophys. Aeromech, Vol. 17, 2010, pp285-290.

[21] Kwok, K.C.S., Burton, M.D., Abdelrazaq, A.K. Wind-induced motion of tall buildings: Designing for habitability. Wind-Induced Motion of Tall Buildings: Designing for Habitability, 2015, pp1-66.

[22] Peeters, B. System Identification and Damage Detection in Civil Engineering; Ph.D. Dissertation, Katholieke Universiteit, Leuven. 2000.

[23] Sompong, N., Prombut, P. Effects of bendtwist coupling deformation on the aerodynamic performance of a wind turbine blade. International Journal of GEOMATE, Vol. 12, Issue 34, 2017, pp15-20.

Copyright (C) Int. J. of GEOMATE All rights reserved, including making copies unless permission is obtained from the copyright proprietors. 